\title{
Mastication force analysis on the fulcrum point of first class lever on lower jaw distal free end denture
}

\author{
Rachman Ardan \\ Department of Prosthodontics Faculty of Dentistry Universitas Padjadjaran
}

\section{ABSTRACT}

The problem in first class free end lever (distal extension base) Removable Partial Denture (RPD) is the lever force on the retention point that may harm the abutment tooth which has been discussed many times, but the amount of force on the fulcrum point (rest) on the abutment tooth has never discussed yet. The objective of this paper is to analyze the amount of force on the fulcrum point in first class lever of lower free end denture on the two dimension static models. The analysis result reveals that the force on the fulcrum point is bigger than the mastication force on the free end saddle, or the force on the fulcrum point is equal with the sum of the force on the saddle and the force on the retention point. The force on the fulcrum point may cause trauma to the periodontal tissue of the abutment tooth. To decrease the amount of force on the fulcrum point is by mastication force limitation, decreasing the distance between the mastication point and the fulcrum point; and increasing the distance between retention point and fulcrum point. For clinical application, there are many biological variables to be considered.

Key words: Mastication force, free-end

\section{INTRODUCTION}

Distal free end denture has more problems compared to all tooth supported denture. Kennedy tooth lost classification which is based on the topographic area pronged it as first class..$^{1-5}$ It indicates that distal free end denture requires special handling. The problem is unstable denture because there is no abutment tooth on the distal side of the free end saddle. Instability happens in vertical, horizontal, and distal directions.

In vertical force direction, because there is no abutment tooth on the distal side of the free end saddle, denture support compressibility between abutment teeth (with occlusal rest) and alveolar mucosa, or between alveolar mucosa near abutment and alveolar mucosa on the distal part of the free end saddle is different. This condition is especially found in lower jaw, because on the area molar and retromolar, compressibility of the alveolar mucosa is very high. Research of Machmud ${ }^{6}$ shows that compressibility of edentulous mucosa in lower jaw is more compressive towards posterior. Compressibility average in area first premolar $=$ $0,34 \mathrm{~mm}$; second premolar $=0,42 \mathrm{~mm}$; First molar $=0,6 \mathrm{~mm}$; second molar $=1,31 \mathrm{~mm}$; third molar $=$ $2,4 \mathrm{~mm}$; and in retromolar pad area $=4,0 \mathrm{~mm}$.

Unstable denture, at the time of mastication will cause leverage, and the center of rotation is on the nearest fulcrum point, and that is the nearest rest seat with its occlusal rest. Leverage could happen in vertical direction, horizontal, 
or combination. The main function of tooth is for mastication, hence the leverage of free end denture in vertical direction is a bigger problem compared to other directions (Fig. 1). The design of retainer unit in free end denture could be first class lever or second class lever.

If the design of retainer unit is first class lever, the denture is more stable to mastication force compared to second class lever design, so that less alveolar ridge resorption on free end saddle. The disadvantage of this design is the abutment will be levered up, so that if it happened continuously, it will harm the abutment tooth. Upraised free end saddle by sticky food in design first class lever prevented by indirect retainer in anterior.

Design retainer second class lever is different than the first lever. The denture is less stable compare to the first class lever and it causes more resorption of alveolar ridge, increase instablility and so on. Patient also feel less comfortable, besides the irritation and the ill taste generates at supported mucosa. Unstable denture also will reduce the efficiency and effectivity of mastication.

The calculation of force value should be considered, because although periodontal membrane is designed to resist the mastication force, if the level is higher, it will generate problems. The aim of this study is to analyze level of force at the fulcrum point on abutment tooth in the case of Kennedy first class tooth lost classification.

\section{METHOD AND ANALYSIS}

To analyze the value of force on fulcrum point, a design of two dimension static model in sagital direction that shows, denture, distal free end saddle, fulcrum point (the arm rest on abutment tooth), and retention point (representative of the $1 / 3$ tip of retentive arm). Denture is described as a horizontal straight bar. The bar in this model supported by most distal fulcrum point (occlusal rest). Mastication force works on free end saddle. Retention point is on the other tip of the bar. The fulcrum point is positioned between the mastication force (free end saddle) and the retention point (Fig.1 and 2).

When there is mastication force $(=\mathrm{mF})$,

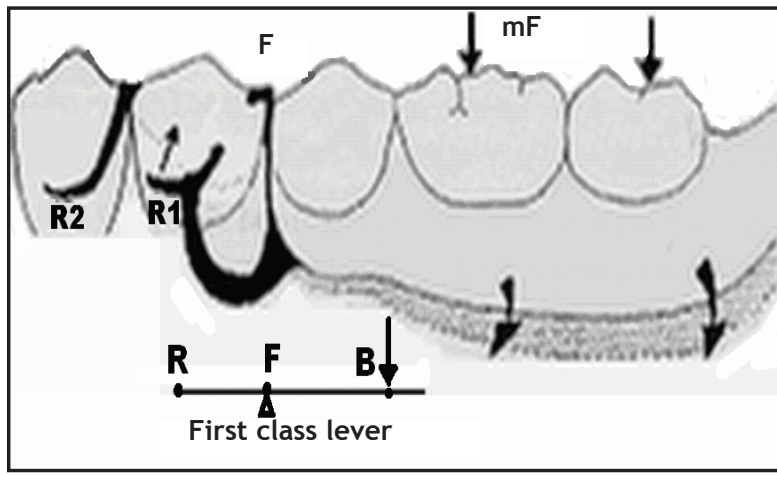

Figure 1. First class lever on free end RPD.

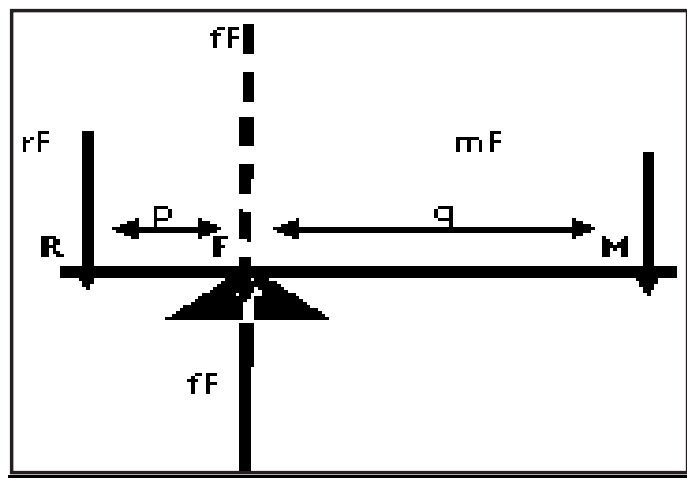

Figure 2. The Design of the first class lever on two dimension model RPD.

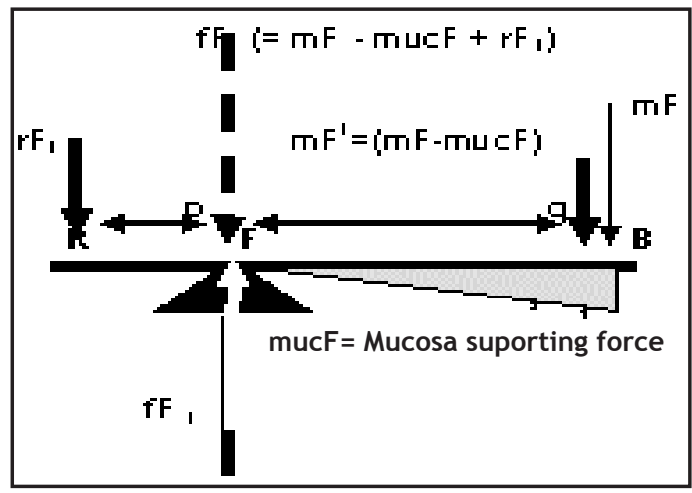

Figure 3. Two dimension model of RPD, first class lever by cosidering mucosa support.

Note: $F=$ Fulcrum (fulcrum point); $R=$ Retention point; $M=$ Mastication point; $p=$ distance from $F$ to $R ; q=$ distance from $F$ to $\mathrm{M}$; $\mathrm{mF}=$ Mastication Force; $\mathrm{fF}=$ force on fulcrum point; $\mathrm{fF}^{\prime}=$ reaction force; $\mathrm{rF}=$ force on retention point

the bar (denture) will rotated around the center of rotation on the fulcrum point the static condition (non-movable) is reached. Retention point which is located in undercut area will lift the abutment tooth to the upward and backward direction. The amount of retentive force is $=r F$.

Retentive force $=\mathrm{rF}$, it means that when abutment is raised by retentive arm, when the 
static condition is reached, as reaction there is an equal value force to the retentive arm (part of the denture) $(=r F)$ (Fig. 2). Level or value of $\mathrm{rF}$ is determined by the amount of $\mathrm{mF}$ and by the comparison between $\mathrm{R}$ to $\mathrm{F}$ distance and to distance $F$ to $M$. There by mechanically the value of $\mathrm{rF}$ is countable as follows

$$
\mathrm{rF}=\mathrm{q} / \mathrm{p} \times \mathrm{mF}
$$

If a static situation has been reached, resultant of $\mathrm{mF}$ and $\mathrm{rF}$ is $\mathrm{fF}$. The value of $\mathrm{fF}$ is equal to the sum of $\mathrm{rF}$ and $\mathrm{mF}$.

$$
\begin{aligned}
f F & =m F+q / p \times m F \\
& =(1+q / p) m F
\end{aligned}
$$

Because value of $\mathrm{rF}$ has been known, hence countable the fF value can be retrieved based on value $\mathrm{mF}$ :

$$
f F=m F+r F
$$

Conclusion from above equation is that occlusal rest pressure (fF) to rest seat on abutment tooth is always bigger than mastication force $(\mathrm{mF})$. The smallest pressure on fulcrum point $(=0)$ will only equal to mastication force if $p$ value $=\sim$ (infinite), and it is impossible. The fF value will always be bigger than $\mathrm{mF}$ value. The more posterior teeth that are lost for free end denture (long free end), The bigger $\mathrm{fF}$ value compared to $\mathrm{mF}$ value.

According to $\mathrm{Gibs}^{7}$ the value of mastication force is between 19,5 kgs. up to $26,7 \mathrm{kgs}$ (median value $=23,1 \mathrm{kgs}$ ). This value is for natural tooths, while for artificial tooth it would be smaller. A study performed by Fadil ${ }^{8}$ shows that the maximum functional mastication force of lower jaw canine is between $12,2 \mathrm{kgs}$. up to $20,9 \mathrm{kgs}$ (median value $=16,55 \mathrm{kgs}$ ). the value in Lower premolar would be smaller than canine, value hence, in RPD case with occlusal rest on premolar, the pressure is far above its functional maximum ability. It would hardly endanger the premolar tooth which is used as a support.

In the clinical reality, support for distal free end denture is not merely from occlusal rest only, but also from attached mucosa. ${ }^{9}$ As a result, when the lever reach static condition, the effect of mastication force on fulcrum point would be smaller. There is a wider free end base saddle, therefore a smaller effect of $\mathrm{mF}$ on fulcrum point in the static condition is found. Extension of the free end base will minimize force per square, so the saddle turn down will be less.

\section{SOLUTION}

Based solely on the equation above, the ways to overcome the problem in reducing the pressure in the main fulcrum point are: (1) Minimize $q$ value. The distance from mastication point $(M)$ to main fulcrum point $(F)$ should be as near as possible. So the numbers of artificial teeth on the free end saddle should as less as possible, for example until the first molar tooth. (2) Increase $p$ value. It means that the retention point $(\mathrm{rF})$ should be placed as anterior as possible. (3) Minimize the $\mathrm{mF}$ value.

The $\mathrm{mF}$ Value can be minimized for example by minimizing the occlusal surface area of artificial teeth on the free end saddle, but it should be balanced with the mastication efficiency and effectivity. The $\mathrm{mF}$ value also can be minimized by giving instruction to patient to avoid heavy mastication load on the free end saddle.

Another way to overcome the problem beside analyzing the equation is by increasing the ability of supporting mucosa tissue in the area free end saddle, for example with: implant ${ }^{1,9,10}$, stress breaker ${ }^{10}$, flexible retentive clasp $\mathrm{arm}^{9}$, impression technic ${ }^{11,12}$, additional retention and support from the opposing side, extending base until maximum (muscle trimming) for free end saddlem, and so on.

\section{CONCLUSION}

Distal free end RPD has more problems which requires special handling. The main problem of distal free end RPD is unstabillity, the first class lever retainer design on distal free end RPD generates leverage to the abutment tooth, and creates cumulative pressure in main fulcrum point, and exceeds the ability of abutment, to minimize pressure on the main fulcrum point: a) Minimize mastication force: eats more soft food; b) Reduce the distance between the bite location and the fulcrum point; c) Add distance between the retention point and fulcrum point; d) maximize the extension base. 


\section{REFERENCES}

1. Giffin KM. Solving distal extension removable partial denture base movement dilemma: A clinical report. J Prosthet Dent 1996;76(4): 347-9.

2. Keng SB. Acrylic resin labial flange for Kennedy class I partial denture: A clinical report. J Prosthet Dent 1996;75(2):114-6.

3. Navas MTR, Del Campo ML. A new free end removable partial denture design. J Prosthet Dent 1993;70(2):176-8.

4. Boucher LJ, Renner RP. Treatment of partially edentulous patients. St. Louis: C.V. Mosby; 1982.

5. Henderson D, Steffel VL. MC Cracken's partial prosthodontics. $4^{\text {th }}$ ed. St Louis: C.V. Mosby; 1973.

6. Machmud M, Ardan R, Lidan R. Studi kasus pola distorsi vertikal jaringan lunak puncak lingir alveolar berujung bebas rahang bawah. Bandung, Indonesia: Dept. of Prosthodontic Faculty of Dentistry Universitas Padjadjaran; 1996.
7. Gibb CH, Mahan PE, Lundeen HC, Brechnan K, Walsh EK, Halbrook WB. Occlusal forces during chewing and swallowing measured by sound transmission. J Prosthet Dent 1981;46(4):4439.

8. Fadil MR. Beban gigit maksimum fungsional gigi individual diukur dengan alat gigit elektronik. Dissertation. Bandung, Indonesia: Facultas Pasca Sarjana Universitas Padjadjaran 1990.

9. Margo A. Dukungan gigi tiruan sebagian lepasan. In: Buku ajar ilmu gigi tiruan sebagian lepasan, jilid I. Jakarta: Hipokrates 1995. p. 134-50.

10. Mc Cracken WL. Contemporary partial denture design. J Prosthet Dent 2004;92(5):409-17.

11. Leupold RJ. A comparative study of impression procedures for distal extension removable partial denture. J Prosthet Dent 1966;16(4):708-20.

12. Wang HY, Lu YC, Shiau YY, Tsou D. Vertical distortion in distal extension riges and palatal area of cast made by different techniques. J Prosthet Dent 1996;75(3):302-8. 